\title{
High-light-output scintillator for photodiode readout: $\mathrm{Lul}_{3}: \mathrm{Ce}^{3+}$
}

\author{
M. D. Birowosuto, ${ }^{\text {a) }}$ P. Dorenbos, ${ }^{\text {b) }}$ and C. W. E. van Eijk \\ Radiation Detection and Matter, Faculty of Applied Sciences, Delft University of Technology, \\ Mekelweg 15, 2629 JB Delft, The Netherlands \\ K. W. Krämer and H. U. Güdel \\ Department of Chemistry and Biochemistry, University of Bern, Freiestrasse 3, 3000 Bern 9, Switzerland
}

(Received 7 December 2005; accepted 5 April 2006; published online 28 June 2006)

\begin{abstract}
In this paper, we investigated the scintillation properties of $\mathrm{LuI}_{3}: \mathrm{Ce}^{3+}$. Radioluminescence, light output, energy resolution, and $\gamma$-scintillation decay are reported. We find an extremely high light output of $98000 \pm 10000$ photons/MeV. $\mathrm{LuI}_{3}: \mathrm{Ce}^{3+}$ also gives a very high electron-hole (e-h) pair

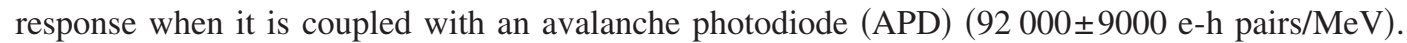
With an APD, a best energy resolution (full width at half maximum over the peak position) of $3.3 \% \pm 0.3 \%$ for $662 \mathrm{keV} \gamma$ quanta is observed. A combination of an extremely high light output and a good energy resolution makes $\mathrm{LuI}_{3}: \mathrm{Ce}^{3+}$ an ideal scintillator for radiation sensor applications. Some drawbacks due to the hygroscopicity and the difficult growth of $\mathrm{LuI}_{3}: \mathrm{Ce}^{3+}$ crystals are also discussed. (C) 2006 American Institute of Physics. [DOI: 10.1063/1.2207689]
\end{abstract}

\section{INTRODUCTION}

The inorganic scintillation detector is widely used as a radiation sensor. Applications are found in fields as different as high energy physics (HEP) research, medical imaging, nondestructive testing, safeguarding, and geological exploration. The scintillator requirements depend on application. The major requirements for high energy physics are high density, fast decay, good radiation hardness, and very low cost, whereas those for medical imaging vary widely. ${ }^{1}$ Single photon emission-computed tomography (SPECT) requires high light output and good energy resolution, while positron emission tomography (PET) requires high density and atomic number, fast decay, and high light output.

Recently, $\mathrm{LaCl}_{3}: \mathrm{Ce}^{3+}$ and $\mathrm{LaBr}_{3}: \mathrm{Ce}^{3+}$ have been discovered and those scintillators exhibit a high light output, a fast decay time, and an excellent energy resolution. ${ }^{2,3}$ However, in order to obtain a higher light output, attention should be directed towards small band gap materials. Scintillation properties of $\mathrm{LuI}_{3}: \mathrm{Ce}^{3+}$ with a smaller band gap $(4.5 \mathrm{eV})$ than that of $\mathrm{LaBr}_{3}: \mathrm{Ce}^{3+}(5.9 \mathrm{eV})$ are reported in Refs. 4-7. Light output of $\mathrm{LuI}_{3}: \mathrm{Ce}^{3+}$ recorded with a photomultiplier tube (PMT) as high as 76000 photons/MeV of absorbed $\gamma$ energy (photons/MeV) reported in Ref. 7 is hitherto the highest light output for a lanthanide trihalide scintillator. Since the location of $5 d-4 f$ emission bands in the $450-650 \mathrm{~nm}$ region is perfectly matched with the sensitivity wavelength range of an avalanche photodiode (APD), $\mathrm{LuI}_{3}: \mathrm{Ce}^{3+}$ also gives a very high electron-hole (e-h) pair response (71 000 e-h pairs/MeV). ${ }^{7}$ The crystals that were investigated were relatively small $\left(2-4 \mathrm{~mm}^{3}\right)$ and contained unwanted rare earth impurities.

In this paper, we present scintillation properties of undoped, $0.5 \%, 1 \%, 2 \%$, and $5 \% \mathrm{Ce}^{3+}$ doped $\mathrm{LuI}_{3}$ with improved crystal quality and larger size $\left(8 \times 6 \times 2 \mathrm{~mm}^{3}\right)$. Light

\footnotetext{
${ }^{a)}$ Electronic mail: m.d.birowosuto@tnw.tudelft.nl

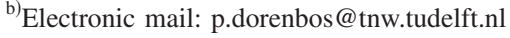

output and energy resolution derived from the pulse height spectra measured with an APD and a PMT are presented. An extremely high light output and an excellent energy resolution are observed. The scintillation decay time and the radioluminescence spectra were also investigated.

\section{EXPERIMENTAL METHODS}

Single crystals of undoped and $\mathrm{Ce}^{3+}$ doped $\mathrm{LuI}_{3}$ were grown by the Bridgmann technique. As starting materials, $\mathrm{LuI}_{3}$ and $\mathrm{CeI}_{3}$ were used. Both were prepared from the elements and sublimed for purification. The growth of high quality single crystal of $\mathrm{LuI}_{3}: \mathrm{Ce}^{3+}$ is quite delicate due to the high melting point of $1323 \mathrm{~K}$ and the extreme sensitivity of the melt against air and moisture. Even at room temperature, $\mathrm{LuI}_{3}: \mathrm{Ce}^{3+}$ crystals are very hygroscopic, and therefore most of the measurements were performed inside a dry box.

$\mathrm{LuI}_{3}$ crystallizes in the $\mathrm{BiI}_{3}$-type structure with space group $R-3 .^{8}$ Due to this layer-type structure, crystals show a platelike habitus and tend to intertwine. Based on its structure and crystal lattice parameters, $\mathrm{LuI}_{3}$ has a calculated density of $5.68 \mathrm{~g} / \mathrm{cm}^{3}$. Together with an effective atomic number of $60.5, \mathrm{LuI}_{3}: \mathrm{Ce}^{3+}$ is better than $\mathrm{LaBr}_{3}: \mathrm{Ce}^{3+}$ with respect to high-energy radiation detection efficiency.

$\gamma$-ray pulse height spectra were recorded with crystals mounted on a $16 \mathrm{~mm}$ diameter Advanced Photonic 630-7073-510 APD. The APD was operated at a bias voltage where the electronic noise and gain are optimum $(1600 \mathrm{~V}){ }^{9}$ In order to avoid gain drift, the APD was stabilized at $278 \mathrm{~K}$. The crystals were mounted without optical coupling on a quartz window placed with optical coupling on top of the APD. This experiment was performed inside an MBraun UNILAB dry box. The crystals were covered with pressed Teflon powder to optimize the light collection. Other pulse height spectra were recorded with a Hamamatsu R1791 PMT inside the same dry box operated with a cathode voltage of $-600 \mathrm{~V}$. The crystals were directly mounted to the window of the PMT without optical coupling and covered with several lay- 


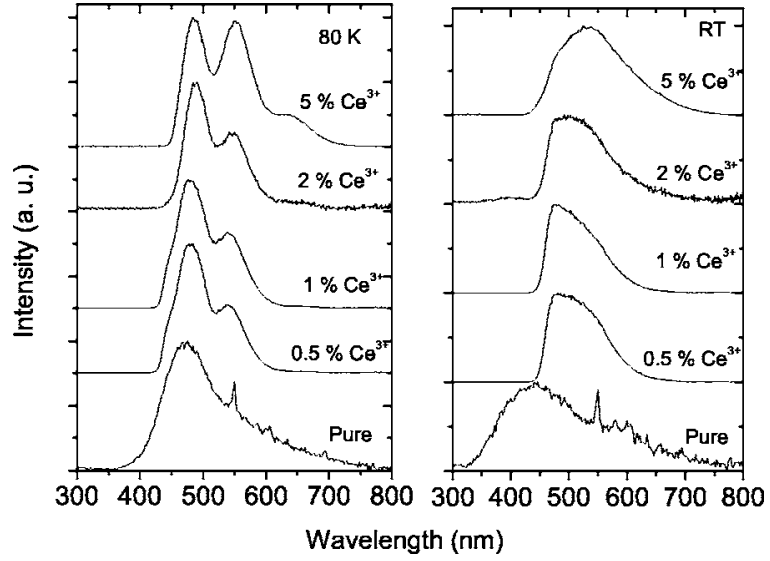

FIG. 1. The radioluminescence spectra of pure and $0.5 \%, 1 \%, 2 \%$, and $5 \%$ $\mathrm{Ce}^{3+}$ doped $\mathrm{LuI}_{3}$ measured at $80 \mathrm{~K}$ and RT. The spectra are corrected for the photodetector quantum efficiency and the monochromator transmission. The spectra were normalized with their maximum intensity and stacked for clarity.

ers of $0.1 \mathrm{~mm}$ UV reflecting Teflon tape. The number of electron-hole pairs created in the APD and the number of photoelectron emitted by the PMT photocathode were determined with standard methods. ${ }^{10}$ Details about determination of light yield and experimental setups for the radioluminescence and scintillation decay time measurements were described elsewhere. ${ }^{7,10}$

\section{RESULTS AND DISCUSSION}

The radioluminescence spectra of undoped, $0.5 \%, 1 \%$, $2 \%$, and $5 \% \mathrm{Ce}^{3+}$ doped $\mathrm{LuI}_{3}$ measured at $80 \mathrm{~K}$ and room temperature (RT) are shown in Fig. 1. For undoped $\mathrm{LuI}_{3}$, the radioluminescence spectrum at $80 \mathrm{~K}$ consists of a broadband peaked at $470 \mathrm{~nm}$. This band is attributed to self-trapped exciton (STE) luminescence. At RT, the peak is shifted to $450 \mathrm{~nm}$. In the undoped $\mathrm{LuI}_{3}$ emission spectrum, sharp peaks are observed due to the rare earth impurities $\mathrm{Tb}^{3+}$ (the highest peak at $550 \mathrm{~nm}$ ) and $\mathrm{Dy}^{3+}$ (the highest peak at $580 \mathrm{~nm}$ ). The radioluminescence spectra of $\mathrm{LuI}_{3}: 0.5 \%, 1 \%$, and $2 \%$ $\mathrm{Ce}^{3+}$ consist of two broad overlapping bands at 472 and $535 \mathrm{~nm}$. These bands are attributed to $\mathrm{Ce}^{3+}$ luminescence and no residual of STE emission is present. ${ }^{7}$

For the radioluminescence spectrum of $\mathrm{LuI}_{3}: 5 \% \mathrm{Ce}^{3+}$ recorded at $80 \mathrm{~K}$, an additional band at $640 \mathrm{~nm}$ is observed. Here we will designate the emission bands at 472 and $535 \mathrm{~nm}$ as the short-wavelength luminescence (SWL) and the band at $640 \mathrm{~nm}$ as the long-wavelength luminescence (LWL). The LWL band is attributed to perturbed sites of $\mathrm{Ce}^{3+}$. In the radioluminescence spectrum of $\mathrm{LuI}_{3}: 5 \% \mathrm{Ce}^{3+}$ recorded at RT, there is an increase in the relative contribution of the LWL band compared to that recorded at $80 \mathrm{~K}$. This increase is accompanied by a decrease of the $472 \mathrm{~nm}$ band of the SWL. Furthermore, all emission bands have become wider at RT.

The ${ }^{137} \mathrm{Cs} \gamma$ source pulse height spectra of $\mathrm{LuI}_{3}: 0.5 \%$ $\mathrm{Ce}^{3+}$ and $\mathrm{LuI}_{3}: 5 \% \mathrm{Ce}^{3+}$ are presented in Fig. 2. For the $0.5 \%$ $\mathrm{Ce}^{3+}$ doped crystal, the $662 \mathrm{keV}$ photopeak at channel number $7330 \pm 10$ is accompanied by a shoulder at lower energy due to the escape of characteristic $K \alpha$ and $K \beta$ x rays of

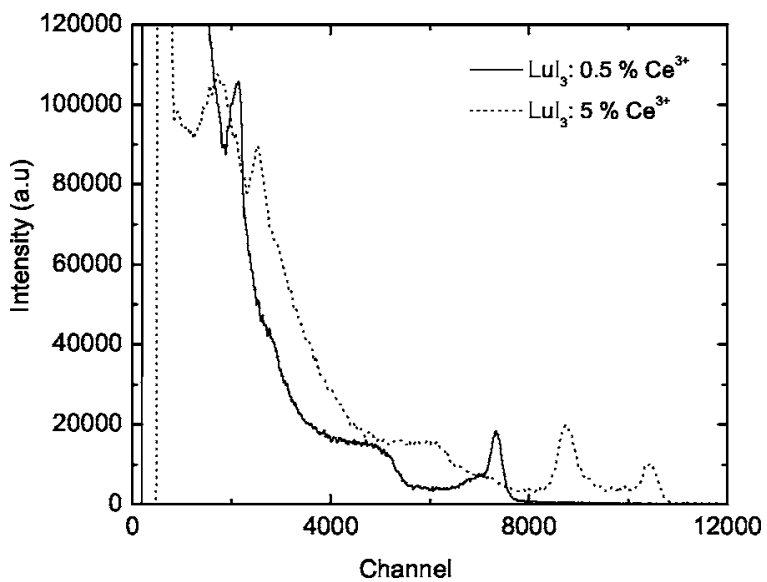

FIG. 2. Pulse height spectra of $\mathrm{LuI}_{3}: 5 \% \mathrm{Ce}^{3+}$ and $\mathrm{LuI}_{3}: 5 \% \mathrm{Ce}^{3+}$ for $662 \mathrm{keV} \gamma$ rays. Spectra were measured with an Advanced Photonic 63070-73-510 APD recorded with shaping time of $0.5 \mu$ s and at $278 \mathrm{~K}$.

lutetium from the small crystal. Two photopeaks are observed for $\mathrm{LuI}_{3}: 2 \% \mathrm{Ce}^{3+}$ (not shown in Fig. 2) and $\mathrm{LuI}_{3}: 5 \%$ $\mathrm{Ce}^{3+}$. This is probably due to poor crystal quality that creates regions of different light output in the crystal.

Electron-hole pair yield, photoelectron yield, light yield, and energy resolution derived from the pulse height spectra under ${ }^{137} \mathrm{Cs} 662 \mathrm{keV} \gamma$-ray excitation recorded with a Photonic 630-70-73-510 APD and a Hamamatsu R1791 PMT at $\mathrm{RT}$ are presented in Table I. For $\mathrm{LuI}_{3}: 2 \% \mathrm{Ce}^{3+}$ and $\mathrm{LuI}_{3}: 5 \%$ $\mathrm{Ce}^{3+}$, two numbers of electron-hole pairs and light yields are presented due to the presence of two photopeaks in the spectra. The energy resolution $R$ [full width at half maximum (FWHM) over peak position] is obtained from a Gaussian fit of the photopeak. ${ }^{11}$

The highest yield recorded with the APD is obtained for $\mathrm{LuI}_{3}: 5 \% \mathrm{Ce}^{3+}(92000 \pm 9000 \mathrm{e}-\mathrm{h}$ pairs/MeV) at $10 \mu \mathrm{s}$ shaping time. The best energy resolution of $3.3 \% \pm 0.3 \%$ is observed for $\mathrm{LuI}_{3}: 0.5 \% \mathrm{Ce}^{3+}$ recorded at $278 \mathrm{~K}$ with shaping time of $0.5 \mu \mathrm{s}$. At this shaping time, a yield of $50000 \mathrm{e}-\mathrm{h}$ pairs $/ \mathrm{MeV}$ is measured. This energy resolution is better than that of $\mathrm{LaCl}_{3}: \mathrm{Ce}^{3+}$ recorded with APD reported by Allier et al. $(3.6 \% \pm 0.4 \%) .{ }^{9}$ Considering the $95 \%-100 \%$ effective quantum efficiency of the APD, the light yield is slightly larger than the number of electron-hole pairs. ${ }^{10}$ The highest light yield of $98000 \pm 10000$ photons $/ \mathrm{MeV}$ recorded with the PMT is obtained for $\mathrm{LuI}_{3}: 5 \% \mathrm{Ce}^{3+}$. This is the highest light yield ever recorded for a lanthanide trihalide scintillator. There is a trend that the light yield is improved towards higher $\mathrm{Ce}^{3+}$ concentration. Nevertheless, $\mathrm{LuI}_{3}: 1 \%$ $\mathrm{Ce}^{3+}$ has a lower light yield than $\mathrm{LuI}_{3}: 0.5 \% \mathrm{Ce}^{3+}$ $(30000 \pm 3000$ photons $/ \mathrm{MeV})$. This fact is attributed to the somewhat worse crystal quality of the $1 \% \mathrm{Ce}^{3+}$ sample under investigation.

Theoretically, the light yield expressed in photons/MeV is given by ${ }^{12}$

$$
Y=10^{6} \frac{S Q}{\beta E_{V C}},
$$

where $S$ is the efficiency of electron-hole transport to the optical center and $Q$ is the luminescence quantum efficiency 
TABLE I. Number of electron-hole pairs, photoelectrons, light yield, and energy resolution derived from pulse height spectra of undoped $\mathrm{LuI}_{3}$ and $\mathrm{LuI}_{3}: 0.5 \%$, $1 \%, 2 \%$, and 5\% $\mathrm{Ce}^{3+}$ under $662 \mathrm{keV} \gamma$-ray excitation measured with an Advanced Photonic 630-70-73-510 APD and a Hamamatsu R1791 PMT at RT. The energy resolution of $\mathrm{LuI}_{3}: 2 \%$ and $5 \% \mathrm{Ce}^{3+}$ is not presented because of poor crystal quality.

\begin{tabular}{|c|c|c|c|c|c|c|c|c|}
\hline \multirow[b]{3}{*}{$\mathrm{LuI}_{3}: \mathrm{Ce}^{3+}$} & \multicolumn{3}{|c|}{ APD } & \multicolumn{5}{|c|}{ PMT } \\
\hline & \multicolumn{2}{|c|}{$\begin{array}{l}\text { Electron-hole pairs } \\
\left(10^{3} \mathrm{e}-\mathrm{h} \text { pairs } / \mathrm{MeV}\right)\end{array}$} & \multirow{2}{*}{$\begin{array}{c}\begin{array}{c}\text { Energy } \\
\text { resolution }\end{array} \\
R(\%)\end{array}$} & \multicolumn{2}{|c|}{$\begin{array}{c}\text { Photoelectrons } \\
\left(10^{3} \text { photoelectrons } / \mathrm{MeV}\right)\end{array}$} & \multicolumn{2}{|c|}{$\begin{array}{c}\text { Light yield } \\
\left(10^{3} \text { photons } / \mathrm{MeV}\right)\end{array}$} & \multirow{2}{*}{$\begin{array}{c}\begin{array}{c}\text { Energy } \\
\text { resolution }\end{array} \\
R(\%)\end{array}$} \\
\hline & $0.5 \mu \mathrm{s}$ & $10 \mu \mathrm{s}$ & & $0.5 \mu \mathrm{s}$ & $10 \mu \mathrm{s}$ & $0.5 \mu \mathrm{s}$ & $10 \mu \mathrm{s}$ & \\
\hline Undoped & $12 \pm 1$ & $15 \pm 2$ & $10.5 \pm 1.1$ & $3.0 \pm 0.3$ & $3.9 \pm 0.4$ & $11 \pm 1$ & $15 \pm 2$ & $11.0 \pm 1.1$ \\
\hline $0.5 \%$ & $50 \pm 5$ & $65 \pm 7$ & $3.3 \pm 0.3$ & $11.1 \pm 1.1$ & $13.5 \pm 1.4$ & $53 \pm 5$ & $65 \pm 7$ & $4.6 \pm 0.5$ \\
\hline $1 \%$ & $21 \pm 2$ & $28 \pm 3$ & $8.1 \pm 0.8$ & $4.7 \pm 0.5$ & $6.4 \pm 0.6$ & $22 \pm 2$ & $30 \pm 3$ & $8.4 \pm 0.8$ \\
\hline $2 \%$ (first Peak) & $58 \pm 6$ & $73 \pm 7$ & $\cdots$ & $12.5 \pm 1.3$ & $15.8 \pm 1.6$ & $58 \pm 6$ & $73 \pm 7$ & $\cdots$ \\
\hline $2 \%$ (second Peak) & $65 \pm 7$ & $82 \pm 8$ & $\cdots$ & $13.9 \pm 1.4$ & $18.2 \pm 1.8$ & $64 \pm 6$ & $84 \pm 8$ & $\cdots$ \\
\hline $5 \%$ (first Peak) & $60 \pm 6$ & $83 \pm 8$ & $\cdots$ & $10.4 \pm 1.0$ & $14.9 \pm 1.5$ & $64 \pm 6$ & $90 \pm 9$ & $\cdots$ \\
\hline $5 \%$ (second Peak) & $72 \pm 7$ & $92 \pm 9$ & $\cdots$ & $12.4 \pm 1.2$ & $16.2 \pm 1.6$ & $76 \pm 8$ & $98 \pm 10$ & $\cdots$ \\
\hline
\end{tabular}

of the optical center. For the ideal scintillator, $S$ and $Q$ are unity. The energy of the band gap between the valence and conduction bands $\left(E_{V C}\right)$ is expressed in eV. $\beta$ is the ratio between the energy needed to create one electron-hole pair and the energy gap. With a $\beta$ value between 2 and 3 and a band gap value of $4.5 \mathrm{eV},{ }^{13}$ the maximal attainable light yield of $\mathrm{LuI}_{3}: \mathrm{Ce}^{3+}$ is between 74000 and 111000 photons $/ \mathrm{MeV}$, respectively. Thus, the light yield from the pulse height experiment (98000 photons/MeV) is comparable with the maximal attainable light yield and $S$ and $Q$ must be close to unity.

Scintillation decay time curves of undoped $\mathrm{LuI}_{3}$ and $\mathrm{LuI}_{3}: 0.5 \%, 1 \%, 2 \%$, and $5 \% \mathrm{Ce}^{3+}$ recorded using the multihit method ${ }^{14}$ are shown in Fig. 3. Figure 4 shows the shorttime scale decay curves recorded using the single stop counting technique. ${ }^{15}$ All decay curves were recorded at room temperature under ${ }^{137} \mathrm{Cs} \gamma$-ray excitation.

The short-time scale decay curve of $\mathrm{LuI}_{3}: 0.5 \% \mathrm{Ce}^{3+}$ has been fitted with a single exponential. Two-exponential fits are necessary for a reconstruction of the scintillation decay curves of $\mathrm{LuI}_{3}: 1 \%, 2 \%$, and $5 \% \mathrm{Ce}^{3+}$ (see Fig. 4).

Up to four decay components are assumed for the scin-

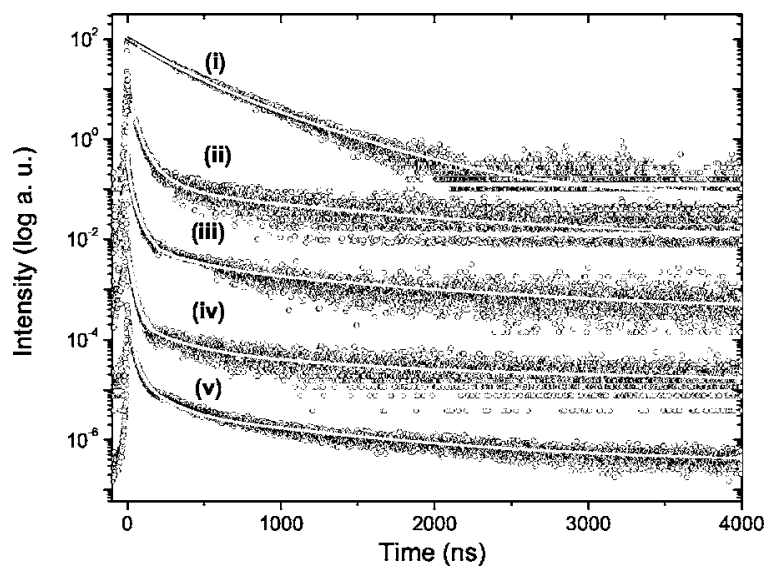

FIG. 3. Long-time scale scintillation decay curves recorded using the multihit method at room temperature of undoped (i), $0.5 \%$ (ii), $1 \%$ (iii), $2 \%$ (iv), and $5 \% \mathrm{Ce}^{3+}(\mathrm{v})$ doped $\mathrm{LuI}_{3}$. The spectra were corrected for the background and the solid lines drawn through the data represent the exponential fits. tillation decay curves in Fig. 3. In Table II, decay components are presented as well as their relative contribution to the total light yield within $4 \mu \mathrm{s}$.

In undoped $\mathrm{LuI}_{3}$, the scintillation decay curve is dominated by two intermediate components of 199 and $550 \mathrm{~ns}$. These components are faster than those of undoped $\mathrm{LuCl}_{3}: \mathrm{Ce}^{3+}$ and $\mathrm{LuBr}_{3}: \mathrm{Ce}^{3+}$ previously recorded by van Loef et al. ${ }^{16}$ The slow decay component has only $2 \%$ contribution to the total light yield.

In $\mathrm{Ce}^{3+}$ doped samples, the scintillation decay curves exhibit a fast decay component of $\sim 35 \mathrm{~ns}$. Additionally, an ultrafast component of $6-10 \mathrm{~ns}$ is observed in the scintillation decay time curves of $\mathrm{LuI}_{3}: 1 \%, 2 \%$, and $5 \% \mathrm{Ce}^{3+}$. The relative contribution of the ultrafast plus fast components to the light yield within $4 \mu \mathrm{s}$ is around $50 \%$. The intermediate decay time component in $\mathrm{Ce}^{3+}$ doped $\mathrm{LuI}_{3}$ has a similar order of magnitude with that recorded for the undoped compound.

The similarity between the fast decay component and the lifetime of the $\mathrm{Ce}^{3+} 5 d$ state of $35 \mathrm{~ns}$ reported in an earlier publication suggests that one energy transfer mechanism in

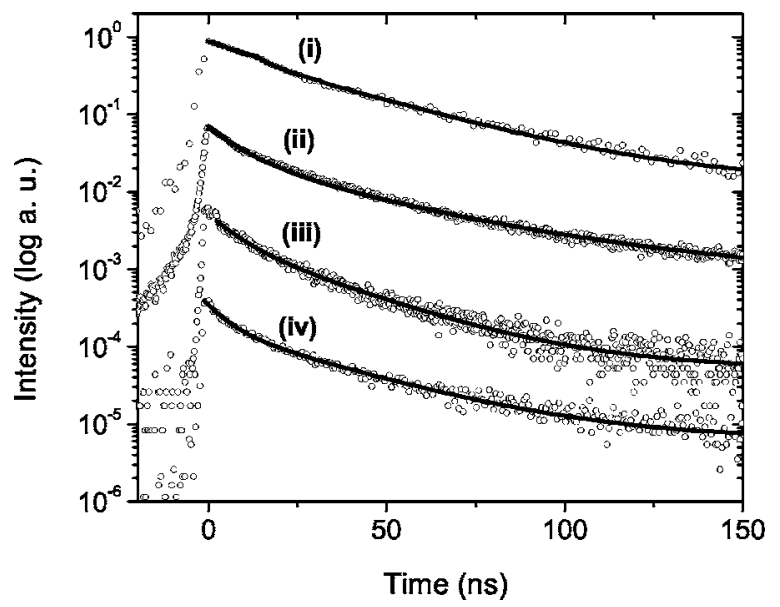

FIG. 4. Short-time scale scintillation decay curves recorded using the single stop counting technique at room temperature of $0.5 \%$ (i), $1 \%$ (ii), $2 \%$ (iii), and $5 \% \mathrm{Ce}^{3+}$ (iv) doped $\mathrm{LuI}_{3}$. The spectra were not corrected for the background and the solid lines drawn through the data represent the fits. 
TABLE II. Characteristic components of the scintillation decay curves of undoped $\mathrm{LuI}_{3}$ and $\mathrm{LuI}_{3}: 0.5 \%, 1 \%$, $2 \%$, and $5 \% \mathrm{Ce}^{3+}$.

\begin{tabular}{|c|c|c|c|c|}
\hline \multirow[b]{2}{*}{$\mathrm{LuI}_{3}: \mathrm{Ce}^{3+}$} & \multicolumn{4}{|c|}{$\begin{array}{l}\text { Decay components } \\
\text { (relative contribution to light yield within } 4 \mu \mathrm{s} \text { ) }\end{array}$} \\
\hline & Ultrafast (ns) & Fast (ns) & Intermediate (ns) & Slow (ns) \\
\hline Undoped & $\cdots$ & $\cdots$ & $\begin{array}{l}199 \pm 20(51 \%) \\
550 \pm 50(47 \%)\end{array}$ & $1200 \pm 120(2 \%)$ \\
\hline $0.5 \%$ & $\cdots$ & $33 \pm 3(57 \%)$ & $115 \pm 12(20 \%)$ & $1100 \pm 110(23 \%)$ \\
\hline $1 \%$ & $10 \pm 1(18 \%)$ & $35 \pm 3(42 \%)$ & $178 \pm 18(11 \%)$ & $1200 \pm 120(29 \%)$ \\
\hline $2 \%$ & $10 \pm 1(19 \%)$ & $32 \pm 3(38 \%)$ & $198 \pm 20(16 \%)$ & $1000 \pm 100(27 \%)$ \\
\hline $5 \%$ & $6 \pm 1(20 \%)$ & $31 \pm 3(30 \%)$ & $140 \pm 14(22 \%)$ & $1000 \pm 100(28 \%)$ \\
\hline
\end{tabular}

$\mathrm{LuI}_{3}: \mathrm{Ce}^{3+}$ is the direct sequential electron-hole capture. ${ }^{13}$ Slow energy transfer from the host lattice to $\mathrm{Ce}^{3+}$ is also present. The radiative energy transfer from STE to $\mathrm{Ce}^{3+}$ is not significant, since the light yield of undoped $\mathrm{LuI}_{3}$ is relatively low compared to that of $\mathrm{Ce}^{3+}$ activated samples (see Table I).

Generally, a faster decay time than the intrinsic $5 d$ lifetime is caused by quenching mechanisms. For example, lifetime shorting by fast transfer to nearly defects can be a plausible cause.

\section{CONCLUSION}

Scintillation properties of samples of pure $\mathrm{LuI}_{3}$ and $\mathrm{LuI}_{3}$ doped with $0.5 \%, 1 \%, 2 \%$, and $5 \% \mathrm{Ce}^{3+}$ were studied. Using an APD, a light output of $92000 \mathrm{e}-\mathrm{h}$ pairs/MeV was recorded for $\mathrm{LuI}_{3}: 5 \% \mathrm{Ce}^{3+}$. A best energy resolution for detection of $662 \mathrm{keV} \gamma$ quanta of $3.3 \%$ (FWHM) was observed for $\mathrm{LuI}_{3}: 0.5 \% \mathrm{Ce}^{3+}$. This energy resolution was recorded at $278 \mathrm{~K}$ with an electronic shaping time of $0.5 \mu \mathrm{s}$; and for that sample, a light output of $50000 \mathrm{e}-\mathrm{h}$ pairs/MeV was observed. The $\gamma$-scintillation decay spectra were also presented. For the $\mathrm{Ce}^{3+}$ doped samples, the number of photons emitted within $50 \mathrm{~ns}$ is about $50 \%$ of the total light yield.

The light yield of $\mathrm{LuI}_{3}: 1 \% \quad \mathrm{Ce}^{3+} \quad(30000 \pm 3000$ photons $/ \mathrm{MeV}$ ) is much lower than that of $\mathrm{LuI}_{3}: 0.5 \% \mathrm{Ce}^{3+}$. This deviating behavior can be caused by the presence of impurities in the $\mathrm{LuI}_{3}: 1 \% \mathrm{Ce}^{3+}$ sample. We also observed two photopeaks in the pulse height spectra of $2 \%$ and $5 \%$ $\mathrm{Ce}^{3+}$ doped $\mathrm{LuI}_{3}$. We hope that further improvements in the technology of $\mathrm{LuI}_{3}: \mathrm{Ce}^{3+}$ crystal growth will eventually produce a superior scintillator with an extremely high light output and a very good energy resolution.

Since $\mathrm{LuI}_{3}: \mathrm{Ce}^{3+}$ is a green-emitting scintillator, the detection with photodiode is very promising and such scintilla- tors could find a wide area of interests. In particular, the very high light output, good energy resolution, and reasonably high density make these crystals of interest for SPECT and PET applications.

\section{ACKNOWLEDGMENTS}

We gratefully acknowledge the support of Netherlands Technology Foundation (STW), the Swiss National Science Foundation, and Saint Gobain, Division of Crystals and Detectors, Nemours, France.

${ }^{1}$ C. L. Mercher, Nucl. Instrum. Methods Phys. Res. A 537, 6 (2005).

${ }^{2}$ E. V. D. van Loef, P. Dorenbos, C. W. E. van Eijk, K. W. Krämer, and H. U. Güdel, Appl. Phys. Lett. 77, 1467 (2000).

${ }^{3}$ E. V. D. van Loef, P. Dorenbos, C. W. E. van Eijk, K. W. Krämer, and H. U. Güdel, Appl. Phys. Lett. 79, 1573 (2001).

${ }^{4}$ P. Dorenbos, C. W. E. van Eijk, H. U. Güdel, K. W. Krämer, and E. V. D. van Loef, Patent No. WO2004109333 (December 16, 2004).

${ }^{5}$ K. S. Shah et al., IEEE Trans. Nucl. Sci. 51, 2302 (2004).

${ }^{6}$ J. Glodo, K. S. Shah, M. Klugerman, P. Wong, W. Higgins, and P. Dorenbos, Nucl. Instrum. Methods Phys. Res. A 537, 279 (2005).

${ }^{7}$ M. D. Birowosuto, P. Dorenbos, C. W. E. van Eijk, K. W. Krämer, and H. U. Güdel, IEEE Trans. Nucl. Sci. 52, 1114 (2005).

${ }^{8}$ L. B. Asprey and T. K. Keenan, Inorg. Chem. 3, 1964 (1140).

${ }^{9}$ C. P. Allier, E. V. D. van Loef, P. Dorenbos, R. W. Hollander, C. W. E. van Eijk, K. W. Krämer, and H. U. Güdel, Nucl. Instrum. Methods Phys. Res. A 485, 547 (2002).

${ }^{10}$ J. T. M. de Haas, P. Dorenbos, and C. W. E. van Eijk, Nucl. Instrum. Methods Phys. Res. A 537, 97 (2005).

${ }^{11}$ O. Guillot-Noël, J. T. M. de Haas, P. Dorenbos, C. W. E. van Eijk, K. W. Krämer, and H. U. Güdel, J. Lumin. 85, 21 (1999).

${ }^{12}$ E. V. D. van Loef, P. Dorenbos, C. W. E. van Eijk, K. W. Krämer, and H. U. Güdel, Nucl. Instrum. Methods Phys. Res. A 537, 232 (2005).

${ }^{13}$ M. D. Birowosuto, P. Dorenbos, J. T. M. de Haas, C. W. E. van Eijk, K. W. Krämer, and H. U. Güdel, J. Lumin. 118, 308 (2006).

${ }^{14}$ W. W. Moses, Nucl. Instrum. Methods Phys. Res. A 336, 253 (1993).

${ }^{15}$ L. M. Bollinger and G. E. Thomas, Rev. Sci. Instrum. 32, 1044 (1961).

${ }^{16}$ E. V. D. van Loef, P. Dorenbos, C. W. E. van Eijk, K. W. Krämer, and H.

U. Güdel, Nucl. Instrum. Methods Phys. Res. A 496, 138 (2003). 